\title{
Fabrication of Mesoporous Polycarbosilane from SBA-15 Templated Polymethylsilane
}

\author{
J. H. Cheon, S. J. Kim, K. J. Choe, and D. H. Park*
}

\author{
Institute of Basic Science, School of Achanced Material \& Engineering, Inje Universitw, Kimhae, Kiongnam 621-749, Korea \\ Received March 25, 2003
}

Key Words : Mesoporous polycarbosilane. Mesoporous silica. SBA-15. Polỵmethỵlsilane

\begin{abstract}
Mesoporous silica materials have been used as templates for syntheses of carbon. ${ }^{1.2}$ metal ${ }^{3}$ and polymer-based ${ }^{+}$mesoporous replicas vio nanocasting process. Since mesoporous silica templates have a narrow pore size distribution and uniform wall thickness. ${ }^{5.6}$ the replicas obtained by synthesis using mesoporous silica templates also have nanometersized pores with a narrow pore size distribution. Incorporation of hydrocarbon polymer through polymerization of monomer such as aniline. ${ }^{j}$ acrylonitrile. ${ }^{8}$ etlyy lene. ${ }^{9}$ methyl methacrylate ${ }^{6 /}$ and phenolformaldehyde ${ }^{\mathrm{jl}}$ within mesoporous MCM-41 could lead to the fabrication of organic nanofibers. Syntheses of mesoporous polymer networks with three dimensional continuity by the replication of mesoporous materials were reported. The preparation of highly ordered macroscopic silicon carbide "2 mesoporous silicon imido nitride $^{13}$ and bimodal porous silicon oxycarbide ${ }^{14}$ from liquid preceramic polymer were also reported. In this communication. we report for the first time the preparation of mesoporous polycarbosilane from liquid polymethylsilane as a polymer precursor and SBA-15 as a template.

The silica mesoporous material SBA-15 used as a template for synthesis of mesoporous polycarbosilane have been synthesized following the procedure in the literature. ${ }^{6}$ The XRD (Rigaku D/Max 2200 diffractometer) pattern of calcined SBA-15 reflected the formation of high quality SBA-15 with hexagonal symmetry (not shown here). Figure l(a) shows transmission electron micrograph (TEM. JEOL JEM-2010) image of rod-shaped calcined SBA-15 with the regular channel array in parallel along the crystallographic c-axis. The external morphology of SBA-15 is rod shape with the length of $c a .1 \mu \mathrm{m}$ and the diameter of $c a .400 \mathrm{~nm}$. as shown in Figure l(a). $\mathrm{N}_{2}$ adsorption-desorption isotherm of calcined SBA-15 was measured using Micromeritics ASAP2010 instrument (Figure 2(a)). Brunauer-EmmettTeller (BET) surface area was $849 \mathrm{~m}^{2} / \mathrm{g}$. the average pore diameter $5.1 \mathrm{~mm}$. total pore volume $1.073 \mathrm{cc} / \mathrm{g}$. and micropore volume $0.058 \mathrm{cc} / \mathrm{g}$. The $\mathrm{d}_{1 \mathrm{jij}}$ spacing calculated from (100) peak at $1.03^{\circ}$ of XRD pattern was $8.6 \mathrm{~mm}$. the unit cell parameter $\left(\mathrm{a}_{\mathrm{c}}=2 \mathrm{~d}_{1 \mathrm{c}} \mathrm{w} / \sqrt{3}\right) .9 .9 \mathrm{~nm}$ and the wall thickness. $4.8 \mathrm{~mm}$.

The agent impregnated to the pore of SBA-15 for the synthesis of polycarbosilane-based mesoporous material was polymethylsilane prepared by polymerization via dehalocoupling of dichloromethylsilane using $\mathrm{Na}$ cataly st as following procedure in the literature. ${ }^{15}$ The number average
\end{abstract}

\footnotetext{
"Corresponding author. Tel: $+82-55-320-3224$; Fax: $+82-55-321-$
} 9718 ; e-mail: chempdhàijnc.inje.ac.kr

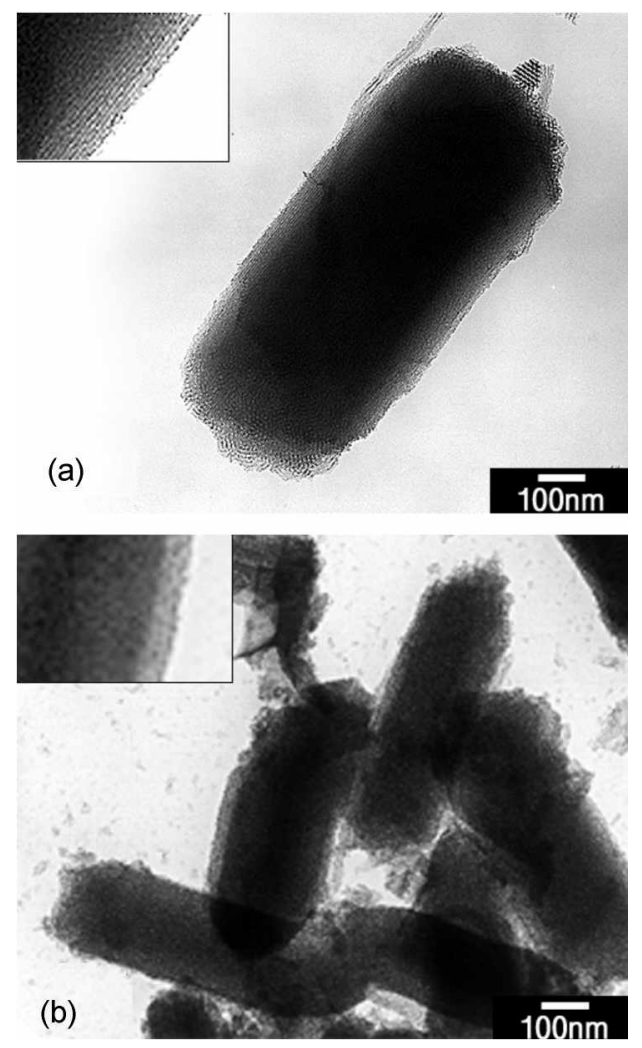

Figure 1. Transmission electron micrographs for (a) templateextracted SBA-15 and (b) silica-extracted mesoporous polycarbosilane atter treated at $600^{\circ} \mathrm{C}$.

molecular weight and the weight average molecular weight of polymethylsilane determined by gel penneation chromatography were 927 and 4120 , respectively:

The synthesis of mesoporous polycarbosilane was perfomed using SBA-15 as a host material and polymethylsilane as a guest material. $0.32 \mathrm{~g}$ of calcined SBA-15 was dried under vacuum of $10^{-3}$ torr. and impregnated with 0.28 $\mathrm{g}$ of polymethylsilane dissolved in $0.5 \mathrm{~mL}$ of toluene in the glove box filled with nitrogen atmosphere. The resultant composite was put into a fused quartz tube equipped with fritted disk. After removal of toluene under vacuum for $24 \mathrm{~h}$ at $160^{\circ} \mathrm{C}$. the composite was heated to $250^{\circ} \mathrm{C}$ at a heating rate of $5{ }^{\circ} \mathrm{Cmin}^{-1}$. cured at $250^{\circ} \mathrm{C}$ for $4 \mathrm{~h}$ and heated at 600 ${ }^{\circ} \mathrm{C}$ for $2 \mathrm{~h}$ in Ar atmosphere. The heat-treated composite was dissolved with stirring for $2 \mathrm{~h}$ in $48 \% \mathrm{HF}$ solution to remove SBA-15 template. The resulting mesoporous polycarbosilane was washed with ethanol/ $\mathrm{H}_{2} \mathrm{O}$ solution and dried at $60^{\circ} \mathrm{C}$ for $12 \mathrm{~h}$. The yield percentage based on the impregnated weight 


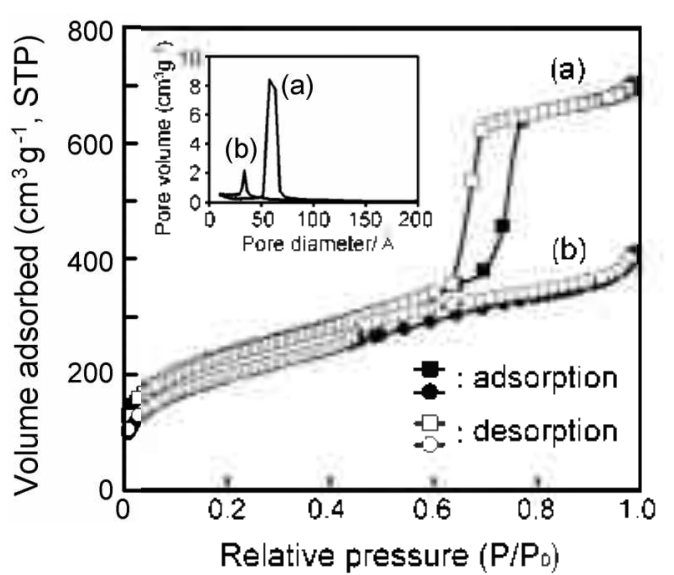

Figure 2. $\mathrm{N}_{2}$ adsorption-desorption isothem for (a) calcined SBA-15 and (b) silica-extracted polvcarbosilane after treated at $600^{\circ} \mathrm{C}$. Inset shows the pore size distribution of (a) calcined SBA-15 and (b) mesoporous polycarbosilane.

of polymethylsilane was $68 \%$. The transformation of poly methylsilane to polycarbosilane within mesopore in SBA-15 was confinmed by infrared spectroscopy (Shimadzu Corp. FT-IR-820IPC) (not shown here). The appearance of band at $1023 \mathrm{~cm}^{-1}$ (Si-C-Si) and the decrease of $1239 \mathrm{~cm}^{-1}\left(\mathrm{Si}-\mathrm{CH}_{3}\right)$ can be assigned to the formation of $\mathrm{Si}-\mathrm{C}-\mathrm{Si}$ bond with the breaking of $\mathrm{Si}-\mathrm{CH}_{3}$ bond via Kumada rearrangement. ${ }^{16}$

Figure 1(b) shows the TEM image of silica-extracted mesoporous polycarbosilane after treated at $600^{\circ} \mathrm{C}$. While the particle size of mesoporous polycarbosilane is smaller than that of SBA-15, as shown in Figure I(a), the morphology of polycarbosilane bears a resentblance in shape to that of SBA-15. It indicates that most of polymethysilane incorporated into SBA-15 channel and transformed to polycarbosilane within the channels of SBA-15. That is. it seemis that the mesoporous polycarbosilane generated through the replication of SBA- 15 template. The contraction of particle size may be due to the slurinkage of polycarbosilane framework during the removal of silica. This shrinkage is attributable to the incomplete filling of polymethylsilane in micropore and mesopore of SBA-15 template and weight loss during heat treatment for Kumada rearrangement. These lead to the irregularity of pore array of mesoporous polycarbosilane as well as the contraction of particle size.

On the comparison with that of SBA-15 as shown in Figure 1(a), the pore array of polycarbosilane was disordered. indicating that this material does not completely replicate. $\mathrm{N}_{2}$ adsorption-desorption isotherm of polycarbosilane reflects the formation of mesopore, as shown in Figure 2(b). The BET surface area was $703 \mathrm{~m} / \mathrm{g}$. the total pore volume at 0.9904 of $\mathrm{P} / \mathrm{P}_{\mathrm{i}}, 0.64 \mathrm{cc} / \mathrm{g}$ and micropore volume. $0.015 \mathrm{cc} / \mathrm{g}$. The curve (b) in inset of Figure 2 shows the pore size distribution of mesoporous polycarbosilane. The average pore diameter calculated by $\mathrm{BJH}$ method from the desorption branch of isothem was $3.6 \mathrm{~mm}$.

As shown in Figure 3, ${ }^{2} \mathrm{Si}-\mathrm{MAS}$ (magic angle spiming) NMR (Bruker DSX $400 \mathrm{MHz}, 4 \mathrm{~mm} \mathrm{ZrO}$ rotor) spectrum of mesoporous polycarbosilane has two broad peaks at -4.8 and

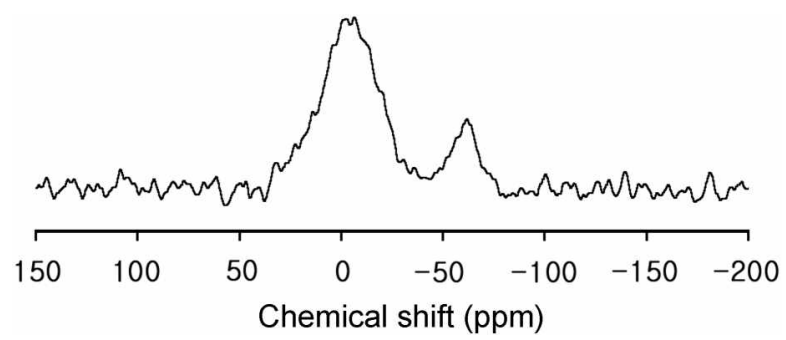

Figure 3. ${ }^{29}$ Si-MAS NMR of silica-extracted mesoporous polycarbosilane after treated at $600^{\circ} \mathrm{C}$.

$-62.0 \mathrm{ppm}$. The peak at $-4.8 \mathrm{ppm}$ can be assigned to Si $(83$ atomic \% from NMR peak area) of polycarbosilane framework. another peak at $-62.0 \mathrm{ppm}$ to $\mathrm{Si}$ (17 atomic \%) of polycarbosilane bonded to oxygen. which comes from the silica surface of SBA-15 during thermal treatment. That is, the hydroxy group of the surface silanol of SBA-15 combined to polycarbosilane during thermal treatment may be resided after HF treatment. while most of silica framework of SBA- 15 were removed by HF treatment. The removal of silica framework as a template is confirmed by the absence of the peak at $c a .-110$ ppm in ${ }^{29}$-MAS NMR. The presence of oxygen in mesoporous polycarbosilane is evidenced by the results of EDX (energy dispersive X-ray spectroscopy. KEVEX Corp. KEVEX superdry detector) measurement showing 54 at. $\%$ of Si. 42 at. $\%$ of $\mathrm{C}$ and 4 at. $\%$ of $\mathrm{O}$.

It is expected that the regularity of polycarbosilane mesopore can be improved by the control of the average molecular weight of polymer precursor and the condition for themmal treatment.

Acknowledgment. This work was supported by grant No. 03142002001 from the Industrial Technology Development Support Program of Ministry of Commerce. Industry and Energy:

\section{References}

1. Ryoo. R.: Joo. S. H.: Jun1. S. J. Phys. Chem. B 1999. 103. 7743.

2. Jun. S.: Too. S. H.: Ryoo. R.: Kruk. M.: Taronire. M.: Liu. Z.: Oshuna. T.: Terasaki. O. J Ant Chem. Soc. 2000. 122. 10712.

3. Shin. H. J.: Ko, C. H; Ryoo. R. J. Mater Chem $2001,11,260$.

4. Kim. J. Y; Yoon. S. B.; Kooli, F; Yu. J.-S. J. Mater Chen 2001. 11. 2912.

5. Kresge. C. T.: Leonowicz. M. E.: Roth. W. J.: Vatuli. T. C.: Beck. J. S. Natwe 1992. 359.710.

6. Zhao. D.: Feng. J.: Huo. Q: Melosh. N.: Fedrickson. G. H.: Chmelka. B. F; Stuchy, G. D. Science 1998. 279. 548

7. Wu. C. G.: Bein. T. Science 1994, 26t. 1757.

8. Wu. C. G.: Bein, T. Science 1994, 266. 1013

9. Kageyama. K.: Tamazawa. J.-I.: Aida. T. Science 1999. 285.2113

10. Moller. K.: Bein. T.: Fischer. R. X. Chem. Hater 1998. 10. 1841.

11. Johnsont. S. A.: Khushalani. D:: Coombs. N.: Mallouk. T. E: Ozin. G. A. J. Mater Chem. 1998, 8,13

12. Sung I.-K.: Yoon, S.-B.: Yu. J.-S.: Kim, D.-P. Chem Conmum. 2002. 1480 .

13. Kaskel. S.: Fanusseng. D.: Schlichte. K. Chom. Conmun. 2000.2481.

14. Schmidt. H.: Koch. D.: Grathwohl. G.: Colombo. P. J. Am. Ceram. Soc. 2001. 84. 2252

15. Mu. Y: Laine, R. M: Harrod, J. F. Appl. Uhgononetal Chent. 1994. 8,95

16. Kumada, M.: Tamao, K. Ad: Organometal Chem 1968.19,6. 